\title{
HUBUNGAN ANTARA KEPEMIMPINAN VISIONER DAN EFIKASI DIRI DENGAN PRODUKTIVITAS KERJA GURU
}

\author{
Yun Soung Suk ${ }^{1}$, Sumardi ${ }^{2}$, Karantiano Sadasa Putra ${ }^{2}$ \\ ${ }^{1}$ Guru Bahasa Indonesia , Jakarta, DKI Jakarta \\ ${ }^{2}$ Program Pascasarjana Universitas Pakuan, \\ Email: pasca@unpak.ac.id
}

\begin{abstract}
The purpose of this study is to analyse the correlation of visionary leadership and self efficacy to teacher's work productivity. This study is conducted in primary public school in District of Tamansari. The study population is 168 teachers and the number of sample is 118 teachers decided by proportional random sampling. Data were collected by questionnaire. The data analysis technique applied correlation regression partial and multiple. The result shows that there is positive correlation between vissionary leadership and teacher's work productivity (the correlation coefficient $r_{y 1}=0,530$ and the detemination coefficient $\left.r_{y l}^{2}=0,281\right)$, there is positive correlation between self efficacy and teacher's work productivity (the correlation coefficient $r_{y 2}=0,472$ and the determination coefficient $\left.r_{y 2}^{2}=0,222\right)$, and there is positive correlation of visionary leadership and self efficacy to teacher's work productivity (the correlation coefficient $r_{y 12}=0,562$ and the determination coefficient $\left.R_{y .12}^{2}=0,316\right)$. Based on the result, it can be concluded that the teacher's work productivity could be enhanced through visionary leadership and self efficacy either partially or concurrently.
\end{abstract}

Keyword: teacher's work productivity, visionary leadership, self efficacy

\begin{abstract}
ABSTRAK
Penelitian ini bertujuan untuk meneliti hubungan antara kepemimpinan visioner dan efikasi diri dengan produktivitas kerja guru. Penelitian dilaksanakan di SD Negeri se-Kecamatan Tamansari pada Desember tahun 2018. Populasi penelitian berjumlah 168 guru dan jumlah sampel sebanyak 118 guru dengan menggunakan proportional random sampling. Pengumpulan data untuk setiap variabel yang diteliti menggunakan angket dengan skala likert. Teknik analisis menggunakan korelasi parsial dan korelasi ganda. Hasil penelitian menunjukkan terdapat hubungan positif antara kepemimpinan visioner dengan produktivitas kerja guru (koefisien korelasi $r_{y 1}=0,530$ dan koefisien determinasi $r^{2}=0,281$ ), terdapat hubungan positif antara efikasi diri dengan produktivitas kerja guru (koefisien korelasi $\mathrm{r}_{\mathrm{y} 2}=$ 0,472 dan koefisien determinasi $r_{\mathrm{y} 2}^{2}=0,222$ ) serta terdapat hubungan positif dan sangat signifikan antara kepemimpinan visioner danefikasi diri secara bersama-sama dengan produktivitas kerja guru (koefisien korelasi $r_{\mathrm{y} 12}=0,562$ dan koefisien determinasi $\mathrm{r}_{\mathrm{y} 12}^{2}=$ 0,316). Dengan demikian dapat disimpulkan bahwa produktivitas kerja guru dapat ditingkatkan melalui kepemimpinan visioner dan efikasi diri baik secara parsial maupun bersama-sama.
\end{abstract}

Kata kunci : produktivitas kerja guru, kepemimpinan visioner, efikasi diri. 


\section{PENDAHULUAN}

Guru merupakan komponen yang paling berpengaruh terhadap tercapainya proses dan hasil pendidikan yang berkualitas. Pekerjaan seorang guru tidak terlepas dari tugas guru sebagai profesi yang meliputi mendidik, mengajar dan melatih. Produktivitas kerja guru pun sangat diperlukan agar tujuan pendidikan dalam menghasilkan lulusan yang berkualitas tercapai. Hal ini penting karena ketika guru memiliki produktivitas yang tinggi maka guru pasti memiliki kemampuan, semangat kerja dan selalu mengembangkan potensi yang dimilikinya untuk membuat peserta didiknya selalu bersemangat dalam belajar.

Keyakinan seseorang guru akan potensinya untuk merencanakan dan menentukan tindakan yang tepat untuk dapat menyelesaikan tugas dan mampu mengatasi rintangan sehingga mampu mencapai tujuan yang lebih baik merupakan wujud efikasi diri yang dimiliki oleh seorang guru yang juga dapat meningkatkan produktivitas dalam bekerja. Masalah tersebut kemudian dirumuskan ke dalam pertanyaan-pertanyaan sebagai berikut: (1). Apakah terdapat hubungan antara kepemimpinan visioner dengan produktivitas kerja guru? (2).Apakah terdapat hubungan antara efikasi diri dengan produktivitas kerja guru?(3). Apakah terdapat hubungan antara kepemimpinan visioner dan efikasi diri secara bersamasama dengan produktivitas kerja guru?

\section{Produktivitas Kerja Guru}

Menurut Malayu (2007:94) produktivitas kerja adalah perbandingan antara output dengan input, dimana output-nya harus mempunyai nilai tambah dan teknik pengerjaannya yang lebih baik. Greenberg (dalam Muchdarsyah, 2009: 12) menyatakan bahwa produktivitas adalah perbandingan antara totalitas pengeluaran pada waktu tertentu dibagi totalitas masukan selama periode tertentu. Malayu (2010:127) mengemukakan International Labour Organization (ILO) menyatakan bahwa produktivitas adalah perbandingan secara ilmu hitung antara jumlah yang dihasilkan dan jumlah setiap sumber yang dipergunakan selama produksi berlangsung. Sejalan dengan ILO, Komariah (2010:16) menyatakan bahwa produktivitas adalah perbandingan terbaik antara hasil yang diperoleh dengan jumlah sumber yang dipergunakan.

Wibowo (2008: 224) Produktivitas adalah rasio dari keluaran terhadap masukan, merupakan ukuran efisiensi manajer dalam menggunakan sumber daya organisasi yang terbatas untuk menghasilkan barang dan jasa. Menurut Paul Mali (dalam Sedarmayanti, 2001: 57), produktivitas adalah bagaimana menghasilkan atau meningkatkan hasil barang dan jasa setinggi mungkin dengan memanfaatkan sumber daya secara efisien. Menurut Whitmore (dalam Sedarmayanti, 2001: 58) Productivity is a measure of the use of the resources of an organization and usually expressed as as a ratio of the output obtained by uses resources to the amount of resources employed.

Berdasarkan teori-teori dari para ahli yang dibahas sebelumnya, dapat disimpulkan bahwa produktivitas kerja guru adalah perbandingan antara hasil kerja (output) guru dengan sumber daya yang digunakan guru (input), dimana output-nya harus memiliki nilai tambah yang lebih baik untuk merealisasikan tujuan pendidikan.

\section{Kepemimpinan Visioner Kepala Sekolah}

Komariah (2012: 81) menyatakan bahwa kepemimpinan yang relevan dengan tuntutan "school based management" dan didambakan bagi produktivitas pendidikan adalah kepemimpinan yang memiliki visi atau visionary leadership, yaitu kepemimpinan yang difokuskan pada rekayasa masa depan yang penuh tantangan. Sebuah visi tercipta dari kreativitas berpikir pemimpin sebagai refleksi profesionalisme dan pengalaman atau hasil elaborasi dan pemikiran mendalam dengan personil lain, yaitu berupa ide-ide tentang cita-cita organisasi di masa depan yang ingin diwujudkan bersama. Akdon (2006: 21) menjelaskan 
secara harfiah arti visi adalah pandangan jauh ke depan (future) yang realistic dan ingin diwujudkan dalam kurun waktu tertentu. Visi bukan utopia, visi tidak sama dengan misi tetapi visi lebih bersifat substantif dari misi.

Dedy (2014: 5) mengemukakan bahwa visi merupakan peluru bagi kepemimpinan visioner. Visi berperan dalam menentukan masa depan organisasi apabila diimplementasikan secara komprehensif. Gaya kepemimpinan visioner menurut Robbins (2003: 195) merupakan kemampuan untuk menciptakan suatu visi yang realistis, dapat dipercaya dan atraktif dengan masa depan organisasi. Berbeda dengan pendapat di atas Diana Kartanegara (dalam Suprayitno: 2007: 119) menyatakan bahwa kepemimpinan visioner adalah pola kepemimpinan yang ditunjukkan untuk memberi arti pada kerja dan usaha yang perlu dilakukan bersama-sama oleh para anggota perusahaan dengan cara memberi arahan, dan makna pada kerja dan usaha yang dilakukan berdasarkan visi yang jelas.

Dari teori-teori para ahli yang dibahas sebelumnya, sintesis dari kepemimpinan visioner kepala sekolah adalah perilaku kepala sekolah yang berorientasi pada pencapaian visi serta mampu mengajak para guru untuk berkomitmen dalam pencapaian tersebut.

\section{Efikasi Diri}

Hollenback (2010: 93-94) efikasi diri mengacu pada penilaian yang dibuat seseorang tentang kemampuan untuk melaksanakan tindakan yang diperlukan untuk menghadapi situasi yang prospektif. Penilaian tersebut menentukan seberapa banyak usaha yang akan dilakukan dan berapa lama mereka akan bertahan menghadapi kendala atau pengalaman yang membuat stres.

Colquit (2009: 180-199) mendefinisikan efikasi diri sebagai keyakinan bahwa seseorang memiliki kemampuan yang dibutuhkan untuk melaksanakan perilaku yang diperlukan untuk keberhasilan tugas. Efikasi diri itu semacam kepercayaan diri atau versi spesifik tugas dari harga diri. Efikasi diri berkaitan dengan kepercayaan untuk dapat melaksanakan perilaku khusus yang diperlukan untuk kesuksesan di tempat kerja. .

Gibson (2012: 13-114) efikasi diri merupakan keyakinan seseorang terhadap keberhasilan dirinya dalam mengatasi situasi sulit. Menurut Anita (2009: h.127), efikasi diri adalah keyakinan seseorang akan kapabilitasnya untuk mengorganisasikan dan melaksanakan rangkaian tindakan yang dibutuhkan untuk menghasilkan pencapaian tertentu. David dan Robert (2010: 117) menyatakan bahwa keyakinan tentang kapabilitas diri untuk dapat menyelesaikan tugas yang diembannya dengan baik. Efikasi diri merupakan keyakinan dari dalam diri seseorang mengenai kemampuan dan kompetensi untuk melaksanakan tugas-tugas secara berhasil (Hidayat 2017).

Berdasarkan teori-teori dari para ahli dapat disimpulkan bahwa efikasi diri adalah sikap seseorang dalam meyakini bahwa dirinya mampu menyelesaikan tugasnya dengan baik.

\section{METODE PENELITIAN}

Penelitian ini merupakan penelitian studi korelasional. Data primer yang dibutuhkan adalah data yang berkaitan dengan kepemimpinan visioner dan efikasi diri serta hubungannya dengan produktivitas kerja Guru PNS di SD Negeri se-Kecamatan Tamansari.

Penelitian ini akan dilakukan pada tingkat SD Negeri yang berlokasi di Kecamatan Tamansari. Penelitian di lakukan pada Bulan Oktober 2017 sampai dengan Bulan Februari 2018. Populasi pada penelitian ini adalah guru-guru PNS di SD Negeri se-Kecamatan Tamansari. Populasi tersebut berjumlah 168 orang guru PNS dari 29 SD Negeri yang berada di Kecamatan Tamansari. Dengan sampel sebanyak 118 orang guru. 


\section{HASIL PENELITIAN}

\section{Pengujian Persyaratan Analisis}

\section{Uji Normalitas}

Hasil perhitungan uji normalitas galat baku taksiran $\left(\mathrm{Y}-\hat{\mathrm{Y}}_{1}\right)$ variabel Produktivitas Kerja Guru (Y) atas variabel Kepemimpinan Visioner $\left(\mathrm{X}_{1}\right)$ diperoleh nilai $\mathrm{L}_{\mathrm{hitung}}$ sebesar 0,081 sedangkan nilai $\mathrm{L}_{\text {tabel }}$ pada taraf signifikansi 0,05 dan $\mathrm{n}=118$ sebesar 0,082 . Persyaratan normal adalah $\mathrm{L}_{\text {hitung }}<\mathrm{L}_{\text {tabel }}$ dengan demikian galat baku taksiran $\left(\mathrm{Y}-\hat{\mathrm{Y}}_{1}\right)$ variabel Produktivitas Kerja Guru $(\mathrm{Y})$ atas variabel Kepemimpinan Visioner $\left(\mathrm{X}_{1}\right)$ memiliki data yang berdistribusi normal.

Hasil perhitungan uji normalitas galat baku taksiran $\left(\mathrm{Y}-\hat{\mathrm{Y}}_{2}\right)$ variabel Produktivitas Kerja Guru (Y) atas variabel Efikasi Diri $\left(\mathrm{X}_{2}\right)$ diperoleh nilai $\mathrm{L}_{\text {hitung }}$ sebesar 0,080 sedangkan nilai $\mathrm{L}_{\text {tabel }}$ pada taraf signifikansi 0,05 dan $\mathrm{n}=118$ sebesar 0,080 . Persyaratan normal adalah $\mathrm{L}_{\text {hitung }}<\mathrm{L}_{\text {tabel }}$ dengan demikian galat baku taksiran $\left(\mathrm{Y}-\hat{\mathrm{Y}}_{2}\right)$ variabel Produktivitas Kerja Guru $(\mathrm{Y})$ atas variabel Efikasi Diri $\left(\mathrm{X}_{2}\right)$ memiliki data yang berdistribusi normal.

\section{Uji Homogenitas}

Pengujian homogenitas varians dilakukan dengan menggunakan uji Bartlett. Persyaratan data homogen adalah apabila nilai $\chi^{2}$ hitung lebih kecil dari $\chi_{\text {tabel }}^{2}$ pada taraf signifikansi 5\%. Dari hasil perhitungan uji homogenitas variabel Produktivitas Kerja Guru atas variabel Kepemimpinan Visioner diperoleh nilai $\chi_{\text {hitung }}^{2}$ sebesar 31,62 sedangkan $\chi_{\text {tabel }}^{2}$ pada taraf signifikansi $5 \%$ dan $\mathrm{dk}=41$ sebesar 56,94 . Karena $\chi_{\text {hitung }}^{2}<\chi_{\text {tabel }}^{2}$, dengan demikian dapat disimpulkan bahwa kelompok data Produktivitas Kerja Guru atas variabel Kepemimpinan Visioner berasal dari populasi yang homogen.

Pengujian homogenitas dilakukan dengan menggunakan uji Bartlett. Berdasarkan hasil pengujian diperoleh nilai $\chi_{\text {hitung }}=48,24$ sedangkan $\chi_{\text {tabel }}^{2}=49,80$ dengan galat $5 \%$ dan derajat kebebasan 35. Persyaratan data tersebut homogen jika $\chi_{\text {hitung }}^{2}<\chi_{\text {tabel. }}^{2}$ Dengan demikian, kelompok skor data Produktivitas Kerja Guru (Y) atas Efikasi Diri $\left(\mathrm{X}_{2}\right)$ berasal dari populasi yang homogen $\left(\chi_{\text {hitung }}^{2}=48,24<49,80=\chi_{\text {tabel }}^{2}\right)$.

\section{Pengujian Hipotesis}

\section{Hubungan antara Kepemimpinan Visioner $\left(X_{1}\right)$ dengan Produktivitas Kerja Guru}

(Y)

Dari hasil perhitungan yang dilakukan dengan uji signifikansi, kekuatan hubungan antara Kepemimpinan Visioner dengan Produktivitas Kerja Guru ditunjukkan oleh koefisien korelasi ry1 $=0,530$ dan koefisien determinasi $\mathrm{r} 2 \mathrm{y} 1=0,281$. Hal ini berarti bahwa Kepemimpinan Visioner memberi kontribusi sebesar 28,1\% terhadap Produktivitas Kerja Guru, sedangkan 71,9\% Produktivitas Kerja Guru dipengaruhi oleh faktor lain.

Berdasarkan hasil analisis regresi sederhana, diperoleh konstanta regresi atau a = 38,859 dan koefisien regresi atau $b=0,625$. Dengan demikian model hubungan fungsional antara Kepemimpinan Visioner dengan Produktivitas Kerja Guru dapat dinyatakan dalam regresi linear sederhana $\hat{\mathrm{Y}}=38,859+0,281 \mathrm{X}_{1}$. Uji linearitas dengan uji $\mathrm{F}$ dilakukan untuk menguji apakah persamaan regresi tersebut linear atau tidak.

\section{Hubungan antara Efikasi Diri $\left(X_{2}\right)$ dengan Produktivitas Kerja Guru (Y)}

Dari hasil perhitungan yang dilakukan dengan uji signifikansi, kekuatan hubungan antara Efikasi Diri dengan Produktivitas Kerja Guru ditunjukkan oleh koefisien korelasi $\mathrm{r}_{\mathrm{y} 2}=$ 0,472 dan koefisien determinasi $\mathrm{r}_{\mathrm{y} 2}^{2}=0,222$. Hal ini berarti bahwa Efikasi Diri memberi kontribusi sebesar 22,2\% terhadap produktivitas kerja guru, sedangkan 77,8\% Produktivitas Kerja Guru dipengaruhi oleh faktor lain. 
Berdasarkan hasil uji-F pada tabel 16, dimana diperoleh $\mathrm{F}_{\text {hitung }}$ sebesar 33,15 dan $\mathrm{F}_{\text {tabel }}$ sebesar 3,92 (dk pembilang $=1$; dk penyebut $=116 ; \alpha=0,05)$ serta $F_{\text {tabel }}$ sebesar 6,86 $(\mathrm{dk}$ pembilang $=1$; dk penyebut $=116 ; \alpha=0,01)$. Karena $F_{\text {hitung }}$ lebih besar dari $F_{\text {tabel }}$ pada taraf signifikansi baik $\alpha=0,05$ maupun $\alpha=0,01$, maka dapat disimpulkan bahwa koefisien korelasi $r_{\mathrm{y} 2}$ sangat signifikan (dalam Sugiyono, 2015: h. 273). Selain itu, berdasarkan hasil perhitungan uji-t diperoleh nilai $t_{\text {hitung }}$ sebesar 5,76 dan nilai $t_{\text {tabel }}$ pada galat $5 \%$ sebesar 1,98 dan pada galat $1 \%$ sebesar 2,62. Karena $t_{\text {hitung }}>t_{\text {tabel}}$, maka koefisien korelasi antara Efikasi Diri dengan Produktivitas Kerja Guru sangat signifikan.

\section{Hubungan antara Kepemimpinan Visioner $\left(X_{1}\right)$ dan Efikasi Diri $\left(X_{2}\right)$ secara bersama-sama dengan Produktivitas Kerja Guru (Y)}

Berdasarkan hasil uji F pada tabel ANAVA, dapat dilihat nila Fhitung sebesar 26,51 sedangkan Ftabel dengan dk pembilang $=2$ dan dk penyebut $=115$ pada taraf signifikansi $\alpha=$ 0,05 sebesar 3,08 dan taraf signifikansi $\alpha=0,01$ sebesar 4,79. Dapat disimpulkan bahwa nilai Fhitung > Ftabel, hal ini menunjukkan bahwa persamaan regresi $\hat{Y}=10,019+0,455 X 1+$ 0,390X2 dapat dipergunakan untuk memprediksi tingkat Produktivitas Kerja Guru melalui Kepemimpinan Visioner dan Efikasi Diri secara bersama-sama.

Kekuatan hubungan antara Kepemimpinan Visioner dan Efikasi Diri secara bersamasama dengan Produktivitas Kerja Guru ditunjukkan oleh koefisien korelasi $r_{\mathrm{y} 12}=0,562$ dan koefisien determinasi $\mathrm{r}_{\mathrm{y} 12}^{2}=0,316$. Hal ini berarti bahwa Kepemimpinan Visioner dan Efikasi Diri secara bersama-sama memberi kontribusi sebesar 31,6\% terhadap Produktivitas Kerja Guru, sedangkan 68,4\% Produktivitas Kerja Guru dipengaruhi oleh faktor lain. Selain itu, berdasarkan hasil perhitungan uji-t diperoleh nilai $t_{\text {hitung }}$ sebesar 7,28 dan nilai $t_{\text {tabel }}$ pada galat $5 \%$ sebesar 1,98 dan pada galat $1 \%$ sebesar 2,62. Karena $t_{\text {hitung }}>t_{\text {tabel}}$, maka koefisien korelasi antara Kepemimpinan Visioner dan Efikasi Diri secara bersama-sama dengan Produktivitas Kerja Guru sangat signifikan.

\section{Uji Korelasi Parsial}

Berdasarkan hasil perhitungan uji korelasi parsial yang pertama diperoleh nilai korelasi parsial antara Kepemimpinan Visioner $\left(\mathrm{X}_{1}\right)$ dengan Produktivitas Kerja Guru (Y) dimana Efikasi Diri $\left(\mathrm{X}_{2}\right)$ dikontrol $\left(\mathrm{R}_{\mathrm{y} 1.2}\right)=0,364$. Berdasarkan hasil uji signifikansi, nilai tersebut sangat signifikansi karena $t_{\text {hitung }}$ lebih besar dari $t_{\text {tabel }}$. Dengan demikian, dapat disimpulkan bahwa terdapat hubungan positif yang sangat signifikan antara Kepemimpinan Visioner dengan Produktivitas Kerja Guru dimana variabel Efikasi Diri dikontrol.

Hasil perhitungan uji korelasi parsial yang kedua diperoleh nilai korelasi parsial antara Efikasi Diri $\left(\mathrm{X}_{2}\right)$ dengan Produktivitas Kerja Guru $(\mathrm{Y})$ dimana Kepemimpinan Visioner $\left(\mathrm{X}_{1}\right)$ dikontrol $\left(\mathrm{R}_{\mathrm{y} 2.1}\right)=0,248$. Berdasarkan hasil uji signifikansi, nilai tersebut sangat signifikansi karena $t_{\text {hitung }}$ lebih besar dari $t_{\text {tabel }}$. Dengan demikian, dapat disimpulkan bahwa terdapat hubungan positif yang sangat signifikan antara Efikasi Diri dengan Produktivitas Kerja Guru dimana variabel Kepemimpinan Visioner dikontrol.

\section{PEMBAHASAN}

\section{Hubungan Positif Antara Kepemimpinan Visioner dengan Produktivitas Kerja Guru}

Hasil uji hipotesis hubungan antara Kepemimpinan Visioner dengan Produktivitas Kerja Guru menunjukkan bahwa nilai kekuatan hubungan ry1 sebesar 0,530 berada pada kategori interval sedang $(0,40-0,599)$ dan nilai koefisien determinasi r2y1 sebesar 0,281 
yang artinya Kepemimpinan Visioner memberi kontribusi dalam peningkatan Produktivitas Kerja Guru sebesar 28,1\%. Signifikansi hubungan ini pun diperoleh hasil yang sangat signifikan pada taraf signifikansi $\alpha=0,05$ dan $\alpha=0,01$.

Terdapat hubungan yang positif antara Kepemimpinan Visioner dengan Produktivitas Kerja Guru. Hal ini dapat dilihat pada hubungan fungsional antara Kepemimpinan Visioner dengan Produktivitas Kerja Guru yang ditunjukkan oleh persamaan regresi $\hat{Y}=38,859+$ 0,625X1 artinya setiap kenaikan satu unit skor Kepemimpinan Visioner dapat meningkatkan skor Produktivitas Kerja Guru sebesar 0,625 pada konstanta 38,859.

Aan Komariah dan Cepy Triatna, $(2012, .82)$ menjelaskan bahwa kepemimpinan visioner adalah kemampuan pemimpin dalam menciptakan, merumuskan, mengkomunikasikan, mensosialisasikan, mentransformasikan dan mengimplementasikan pemikiran-pemikiran ideal yang berasal dari dirinya atau sebagai hasil interaksi social di antara anggota organisasi stakeholders yang diyakini sebagai cita-cita organisasi di masa depan yang harus diraih atau diwujudkan melalui komitmen semua personil. Pemimpin yang visioner mampu mendukung produktivitas kerja guru agar lebih baik lagi.

\section{Hubungan Positif Antara Efikasi Diri dengan Produktivitas Kerja Guru}

Berdasarkan hasil perhitungan analisis data, diperoleh nilai korelasi antara Efikasi Diri dengan Produktivitas Kerja Guru, ry2 = 0,472 dan koefisien determinasi r2y2=0,222 yang artinya hubungan antara Efikasi Diri dengan Produktivitas kerja memiliki hubungan yang cukup kuat dan Efikasi Diri memberikan kontribusi sebesar 22,2\% dalam peningkatan Produktivitas Kerja Guru. Signifikansi hubungan ini pun diperoleh hasil yang sangat signifikan pada taraf signifikansi $\alpha=0,05$ dan $\alpha=0,01$.

Terdapat hubungan yang positif antara Efikasi Diri dengan Produktivitas Kerja Guru. Hal ini dapat dilihat pada hubungan fungsional antara Efikasi Diri dengan Produktivitas Kerja Guru yang ditunjukkan oleh persamaan regresi $\hat{Y}=15,889+0,785 X 2$ artinya setiap kenaikan satu unit skor Efikasi Diri dapat meningkatkan skor Produktivitas Kerja Guru sebesar 0,785 pada konstanta 15,889 .

Hasil penelitian ini didukung oleh Rizki Sandra, dalam tesisnya yang berjudul "Hubungan antara Efikasi Diri dan Iklim Organisasi dengan Produktivitas Pengembangan Profesi Guru" pada tahun 2017, menunjukkan bahwa terdapat hubungan positif dan signifikan antara efikasi diri dan iklim organisasi secara bersama-sama dengan produktivitas kerja guru. Hal ini dilihat pada koefisien korelasinya $\left(\mathrm{r}_{\mathrm{y} 12}\right)$ sebesar 0,60 dengan persamaan regresi $\hat{Y}=48,46+0,359 X_{1}+0,365 X_{2}$.

\section{Hubungan Positif Antara Kepemimpinan Visioner dan Efikasi Diri secara bersama-sama dengan Produktivitas Kerja Guru}

Hubungan secara bersama-sama antara variabel Kepemimpinan Visioner dan Efikasi Diri dengan Produktivitas Kerja Guru, memiliki koefisien korelasi sebesar $r_{\mathrm{y} 12}=0,562$ dan koefisien determinasi $r_{y 12}^{2}=0,316$ sehingga dapat disimpulkan bahwa 31,6\% Produktivitas Kerja Guru dapat ditingkatkan melalui variabel Kepemimpinan Visioner dan Efikasi Diri secara bersama-sama.

Secara parsial, hasil pengujian korelasi ganda ini menunjukkan nilai koefisien korelasi 0,364 ketika Efikasi Diri dibuat konstan dan 0,248 ketika Kepemimpinan Visioner dibuat konstan. Ini menunjukkan bahwa Kepemimpinan Visioner di Kecamatan Tamansari memiliki kekuatan yang lebih dominan dibanding Efikasi Diri. 


\section{SIMPULAN}

Berdasarkan analisis terhadap data hasil penelitian dapat disimpulkan terdapat hubungan positif sangat signifikan antara kepemimpinan visioner dengan produktivitas kerja guru, antara efikasi diri dengan produktivitas kerja guru, antara kepemimpinan visioner kepala sekolah dan efikasi diri secara bersama-sama dengan produkrivitas kerja guru.

Berdasarkan hasil penelitian ini maka untuk meningkatkan produktivitas kerja guru dapat dilakukan dengan meningkatkan kepemimpinan visioner kepala sekolah dan perbaikan pada efikasi diri.

\section{DAFTAR PUSTAKA}

Angelo, Kinici, Mel Fugate. 2012. Organizational behavior: key concept, skills, and best practices. New York: McGraw-Hill Irwin

Colquitt, J.A., J. Lepine, M.J. Wesson. 2011. Organizational Behavior. New York: McGrawHill.

Covey, Stephen R. 2011. Seven Habits of Highly Effective People, Jakarta: Binarupa Aksara.

Gibson, JI, JM Ivancevich, JH Donnelly,Jr., and R Konopaske. 2012. Organization Behavior: structure, process. New York: Mc Graw-Hill

Ivacevich, John M. 2001. Human Resource Management $8^{\text {th }}$ edition.New York: The McGraw-Hill Companies, Inc.

Ivacevich,John M, Robert Konopaske, Michael T. Matteson. 2008. Organizational Behavior and Management. New York: McGraw-Hill International Edition.

Hidayat, Rais. 2017. "Perilaku Etis Dosen Dalam Perspektif Efikasi Diri, Kepemimpinan, Dan Komunikasi Interpersonal.” P E D A G O N A L Jurnal Ilmiah Pendidikan 1(1): 3744.

Schemerhorn, John R. Jr, Richard N. Osborn, Mary Uhl-Bien, James G. Hunt. 2012. Organizational Behavior. New Jersey: John Wiley \& son (asia) Pte Ltd

Kartini Kartono. 2010. Psikologi Sosial untuk Manajemen, Jakarta: CV Rajawali.

Malayu S.P. Hasibuan. 2007. Manajemen Sumber Daya Manusia. Jakarta: PT. Bumi Aksara.

Malayu S.P. Hasibuan. 2010. Organisasi dan Motivasi Dasar Peningkatan Produktivitas. Jakarta: PT. Bumi Aksara.

McShane, Von Glinow. 2015. Organizational Behavior: emerging Knowledge, Global Reality. New York: McGraw Hill International

Miftah Thoha. 2013. Perilaku Organisasi Konsep Dasar dan Aplikasinya, Jakarta: PT. Raja Grafindo Persada.

Miner, JB. 2005. Organizational Behavior: Behavior 1: Essential Theories of Motivation and Leadership, Armonk: M.E. Sharpe 
Montana, Patrick J. dan Bruce H., 2008. Management. Hauppauge, New York: Barron's Educational Series, Inc

Muchdarsyah Sinungan. 2009. Produktivitas Apa dan Bagaimana. Jakarta: PT. Bumi Aksara.

Mulyasa. 2009. Menjadi Kepala Sekolah Profesional. Bandung: PT. Remaja Rosada Karya

Nanus, Burt. 2009. Kepemimpinan Visioner: Menciptakan Kesadaran akan Arah dan Tujuan di dalam Organisasi, diterjemahkan oleh Frederik Ruma dari Visionary Leadership: Creating a Compelling Sense of Direction for Your Organization, Jakarta: PT Prenhallindo. 